Article

\title{
Evaluating Heat Flux Profiles in Aluminum Reheating Furnace with Regenerative Burner
}

\author{
Hang Zhang * and Shengxiang Deng \\ School of Energy Science and Engineering, Central South University, Changsha 410083, China; \\ dengsx@csu.edu.com \\ * Correspondence: zhanghang4202@126.com; Tel.: +86-185-0844-9270
}

Academic Editor: Tapas Mallick

Received: 2 March 2017; Accepted: 18 April 2017; Published: 20 April 2017

\begin{abstract}
Properly understanding heat flux characteristics is a crucial prerequisite to efficiently applying a regenerative burner in an aluminum reheating furnace. A series of experiments was conducted in this study in order to establish a database of the best available burners according to furnace temperature, excess air ratio, and flame combustion mode as they affect heat flux characteristics at the burner plane $(Z=0 \mathrm{~mm})$. A heat flux model was developed to estimate heat transfer in the furnace, and the heat flux proportions of the other two horizontal levels $(Z=400 \mathrm{~mm}$ and $Z=750 \mathrm{~mm}$ ) were investigated. The contour profile of heat flux indicates that total heat flux $(T H F)$ and radiation heat flux $(R H F)$ increases with furnace temperature increment $\left(900-1100{ }^{\circ} \mathrm{C}\right)$. Low excess air ratio $\left(1.2-1.3\right.$, at furnace temperature $\left.1100{ }^{\circ} \mathrm{C}\right)$ not only reduced the heat flux gradient, but also contributed to enlarge high THF areas and the maximum RHF. The flameless combustion mode displayed larger average THF and RHF uniformity than that of conventional combustion mode. Therefore, the burning effect of operating condition 1 (gas velocity, $90 \mathrm{~m} / \mathrm{s}$; excess air ratio, 1.2; flameless combustion) is better than the other conditions. A change of furnace temperature and excess air ratio had mildly effect on convection coefficient, but combustion mode was in contrast. The estimated heat flux distribution from the measured heat flux at the whole burner plane was in agreement with the fitted line of the axis of burner B. Although the intercept of the simulated equation was slightly underestimated, the error can be eliminated by improving the experimental conditions. The results presented here similarly apply to all regenerative burners. A comparison of heat flux among the three horizontal levels indicated that the RHF proportion comprised about $80 \%$ of the THF at each level, and a slightly increase $\left(21.1 \mathrm{~kW} / \mathrm{m}^{2}\right)$ of $T H F$ in the high level from the low levels.
\end{abstract}

Keywords: heat flux; aluminum reheating furnace; regenerative burner; operating conditions

\section{Introduction}

Reheating furnace with regenerative system has been widely applied in the non-ferrous metal industry due to its great advantages, such as high energy efficiency, low pollutant emission and high production yield $[1,2]$. In recent years, the number of regenerative reheating furnace increases rapidly all around the world. However, fluctuation of temperature and pressure and unknown of combustion characteristic at condition of low-oxygen and high-temperature, the result of the regenerative burner working principle, restrict the furnace development [3,4]. In order to make full use of this kind of energy saving technology, we must understand and master the combustion characteristics in the furnace.

Total heat flux (THF) is one of the evaluation standards of combustion process, which includes radiation heat flux $(R H F)$ and convection heat flux. Properly understanding heat flux characteristics in the furnace are of great importance for improving combustion $[5,6]$. More and more studies about heat flux profile in industrial facility, such as circulating fluidized bed boiler [7,8], solar furnace [9], 
Bridgman furnace [10], and reciprocating gas engines [11], have been done. Investigation of influencing factors to heat flux profile is significant work for human controlling combustion process. Several factors are critical to the heat flux distribution. Kang et al. [12] experimentally studied the influence of air co-flow velocities varying on radiation fraction and flame width. The experiment results revealed that as the velocity increased, the radiation fraction and flame width decreased. Hashimoto and Watanabe [13] numerical investigated the effect of the furnace scale on the heat transfer mechanism of coal particles in furnace. Zhang et al. [14] presented the effects of boiler load on the performance of heat flux in a $600 \mathrm{MW}$ supercritical boiler. As a result, the heat transfer is a function of several operating conditions such as excess air ratio [15,16] and furnace temperature [17]. Sadegh et al. [18] established a comprehensive 1.5-D model for CFB (circulating fluidized bed) furnace, resulting in good agreement with the measured heat fluxes. The model predicts that the radiation heat increases with an increase of furnace temperature, and exceeds $70 \%$ of total heat flux for all the cases designed.

Experiment method is always the direct and preferred way to investigate heat flux behaviors in reheating furnace. Many experimental studies on heat flux inside reheating furnace have already been conducted by researchers [19-21] Wikstrom et al. [22] used a model to calculate the transient local surface temperature and heat flux of the steel slab. The experiment results showed a good agreement to model-calculated results. In another work [23], they found that heat transfer intensity and uniformity, inside a semi-industrial test furnace with various industrial regenerative burner, were affected by HiTAC (high temperature air combustion) The convective flux was found to be uniform and as high as $30 \%$ of the total heat flux to an object surface in the furnace.

In this article, a pair of regenerative burners was tested with different operating conditions. Test data include temperature, total heat flux, and radiation heat flux. Reporting the raw data and making a preliminary data evolution were main aims of this article. Different from the previous research work, the distribution of the holes was extensive, so the test data were more comprehensive. In addition, we dealt with measurement error to acquire accurate data. Furthermore, an estimate model of heat flux distribution at burner plane was proposed.

\section{Experiment Test Facility}

\subsection{Furnace with Regenerative Burners}

A typical fuel-fired aluminum reheating furnace is shown in Figure 1. Orthographic views of the reheating furnace and their dimensions are shown in Figure 2 in addition to other details such as the position of the regenerative burners, chamber dimensions, height of the crown, and the aluminum liquid height level. The position coordinates of the 14 observation holes at the furnace roof, i.e., the location where the majority of the data were collected, are explained in Figure 2c. There are also several observation holes on the wall, which were used to measure wall temperature and heat flux parameters. The components of molten aluminum are described in Table 1.

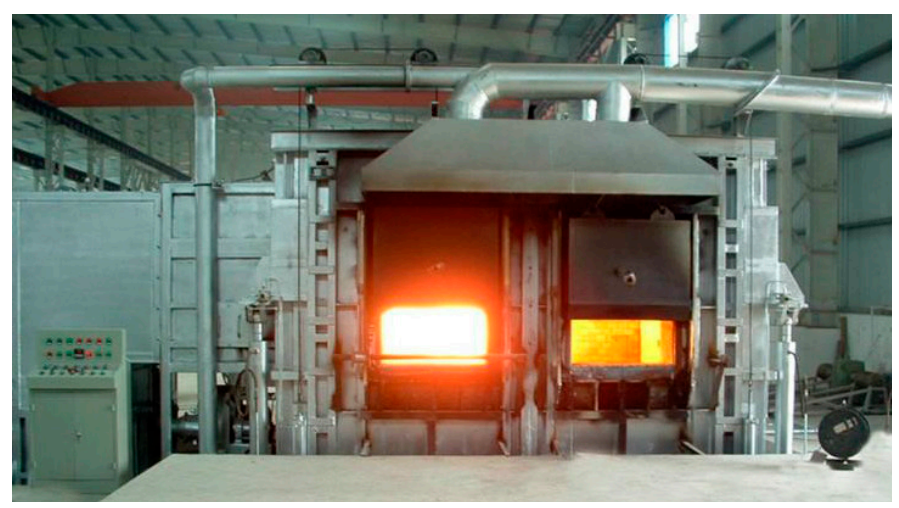

Figure 1. A photograph of the burning aluminum reheating furnace. 


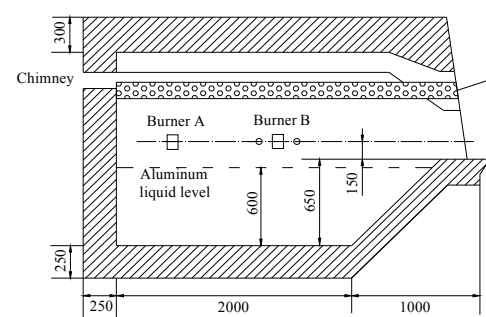

(a) Front view

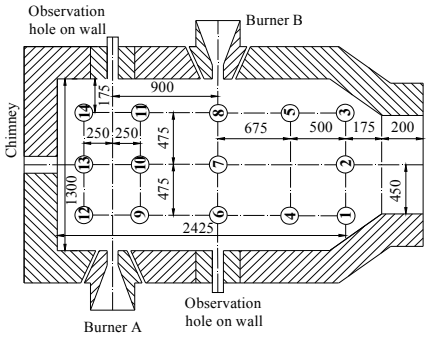

(c) Top view

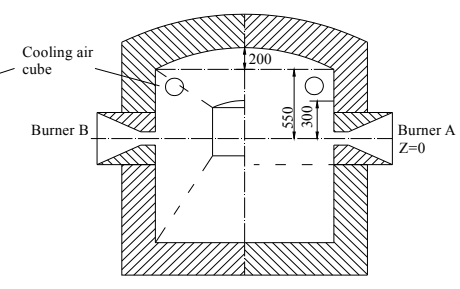

(b) Side view

Figure 2. Orthographic views of the reheating furnace: (a) top view; (b) front view; and (c) side view.

Table 1. The composition of molten aluminum used for these experiment investigations.

\begin{tabular}{cccccccccc}
\hline Element & $\mathbf{C u}$ & $\mathbf{M g}$ & $\mathbf{S i}$ & $\mathbf{F e}$ & $\mathbf{M n}$ & $\mathbf{N i}$ & $\mathbf{Z n}$ & $\mathbf{C a}$ & $\mathbf{A l}$ \\
\hline $\mathrm{wt} \%$ & 1.638 & 0.251 & 10.603 & 0.78 & 0.202 & 0.055 & 0.916 & 0.005 & 85.309 \\
\hline
\end{tabular}

Two HRS-DF1 type regenerative burners (Nippon Furnace Kogyo Kaisha Ltd., Tokyo, Japan) were utilized in this experiment. The pair can be used in both flame and flameless modes with a maximum capacity of $100 \mathrm{~kW}$. The burners were equipped with honeycomb compact regenerators. The burners exchange their function at every cycle: When burner B serves as the combustion burner, burner A works as an outlet and recovers energy from the exhaust gases.

Burner B has two combustion modes: Conventional combustion with preheating of air (F1 mode) and flameless mode (F2 mode). Below $900{ }^{\circ} \mathrm{C}$ in the furnace (wall temperature), burner B works in F1 mode with the honeycomb compact regenerators. A gas-air mixture is provided for combustion, as shown Figure 3a. When the wall temperature exceeds $900{ }^{\circ} \mathrm{C}$, burner B works in F2 mode; gas is supplied separately by two fuel nozzles. Figure $3 b$ shows where the air nozzle has a rectangular shape $(20 \mathrm{~mm} \times 100 \mathrm{~mm})$. The standard diameter of the fuel nozzle is $4.5 \mathrm{~mm}$. The fuel used for these experiments was LPG (>98\%, propane). A schematic drawing of the test furnace in F1 and F2 combustion modes is shown in Figure 3.

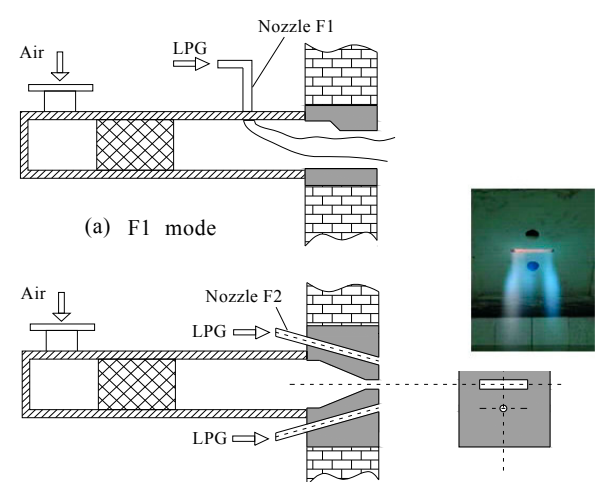

(b) F2 mode

Figure 3. Schematic of regenerative burner manufactured by NFK type HRS-DF1: (a) firing in flame mode with heating up air (F1 mode); and (b) flameless mode (F2 mode). 


\subsection{Measurement Program}

In most studies on this subject $[22,24,25]$, heat flux is measured using a heat flux meter inserted into the furnace through specified ports. The heat flux meter utilized in this study has a steel plug in the tip which measures the rate of heat flow per unit area. An ellipsoidal radiometer [26] and some thermocouples were also used here to record irradiation and temperature information, respectively. The meters and the thermocouples were held inside a water-cooled probe, as shown in Figure 4. The water-cooled probe was inserted into the furnace through the hole at the furnace roof and calibrated at its surface in order to ensure it was in the correct location prior to the experiment.

The temperature gradient between the heat flux meter steel plug and water-cooled probe surfaces were measured, then the total heat flux (THF) was calculated as follows [27]:

$$
q_{\mathrm{T}}=\frac{\lambda\left(T_{\mathrm{S}}-T_{\mathrm{w}}\right)}{L}
$$

where $q_{\mathrm{T}}$ is heat flux incident on the meter; $\lambda$ is the mean thermal conductivity of the plug surface between the two thermocouples; $T_{\mathrm{w}}$ and $T_{\mathrm{s}}$ are the steel and water-cool probe surface temperatures, respectively; and $L$ is the distance between the measurement surfaces.

The radiation heat flux $(R H F)$ is defined to reflect the heat flux spatial distribution:

$$
q_{\mathrm{R}}=\varepsilon_{\mathrm{s}}\left(G_{\mathrm{r}}-\sigma T_{\mathrm{p}}^{4}\right)
$$

where $q_{\mathrm{R}}$ is the radiation flux incident on the meter and $\varepsilon_{\mathrm{s}}$ is the emissivity of the plug surface (equal to 0.98$)$. $G_{\mathrm{r}}$ is the irradiance, $\sigma$ is the Stefan-Boltzmann constant $\left(5.67 \times 10^{-8} \mathrm{~W} \cdot \mathrm{m}^{-2} \cdot \mathrm{K}^{-4}\right)$, and $T_{\mathrm{p}}$ is the temperature measured at the plugs frontal surface.

Convective heat transfer (CHT) coefficient can be calculated according to Equations (3) and (4).

$$
\begin{aligned}
& q_{\mathrm{C}}=q_{\mathrm{T}}-q_{\mathrm{R}} \\
& h_{\mathrm{c}}=\frac{q_{\mathrm{C}}}{T_{\mathrm{f}}-T_{\mathrm{b}}}
\end{aligned}
$$

where $h_{\mathrm{c}}$ is the convective heat transfer coefficient, $q_{\mathrm{C}}$ is the convection heat flux, $T_{\mathrm{f}}$ is the temperature measured of the plug frontal surface, and $T_{\mathrm{b}}$ is the temperature measured of the plug back surface.

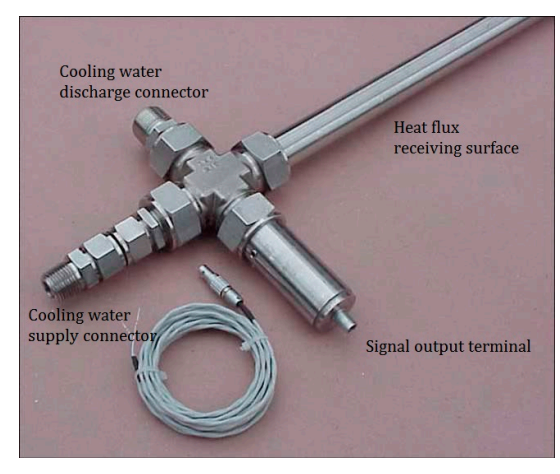

Figure 4. Structure and function of water-cooled heat flux meter.

\subsection{Experiment Uncertainty Analysis}

The uncertainties associated with the heat flux meter positions are $\pm 10 \mathrm{~mm}$ in the $X$ - and Z-directions and $\pm 2 \mathrm{~mm}$ in the Y-direction. The uncertainty of the experimental measurements was calculated based on the combination of the bias error limit, $B$, and the precision error limit [28], $P$ : 


$$
U=\sqrt{\left(B^{2}+P^{2}\right)}
$$

The precision error limit, which can be determined by repeatedly measuring the variable of interest, is related to the standard deviation of the measurements. The standard deviation of the measuring parameters, $\sigma_{\mathrm{s}}$, is given as follows:

$$
\sigma_{s}=\sqrt{\frac{\sum_{i=1}^{n}\left(s_{i}-\bar{s}\right)^{2}}{n_{\text {total }}-1}}
$$

The standard deviation of the mean temperature is related to the standard deviation of measurements:

$$
\sigma_{\bar{s}}=\frac{\sigma_{s}}{\sqrt{n_{\text {total }}}}
$$

The precision error limit in the mean value can be determined as follows [28]:

$$
p=t \sigma_{\bar{s}}
$$

where $t$ is a function of the confidence level and degrees of freedom (DOF). At a $95 \%$ confidence level with a large number of samples (over 30), $t$ equals 2.0. The number of samples taken in this experiment was more than 100 , so the $t$ value was taken as 2.0.

The main source of error in these trials originated in the heat flux meter geometric size and structure. Air lay also has considerable influence over the stability of the heat flow meter and thus can facilitate dynamic measurement.

\subsection{Experimental Conditions}

We ran six other case studies in addition to testing the furnace and regenerative burners described above. The first operating condition (OP1) was made for standard work conditions. Burner B worked in F2 mode, furnace temperature was $1100{ }^{\circ} \mathrm{C}$, and excess air ratio was 1.2. In other cases, at least one operating parameter was changed. In OP2 and OP3, furnace temperature was decreased below the standard case. In OP4 and OP5, excess air ratio was raised to 1.25 and 1.3, respectively. All five tests were run in F2 combustion mode with air preheating. The final case (OP6) was performed under reduced furnace temperature $\left(850^{\circ} \mathrm{C}\right)$ and in $\mathrm{F} 1$ combustion mode without air preheating. The furnace temperature is an average of the wall temperature measured with five thermocouples: Three along the ceiling of the furnace and two at the holes on wall. The furnace temperature was controlled by varying the cooling air flow rate. In all cases, the fuel temperature, air temperature, preheating air temperature, and gas velocity were kept constant. Table 2 describes the results of all six cases.

Table 2. Different operating conditions of six cases.

\begin{tabular}{ccccc}
\hline Case & Gas Velocity $(\mathrm{m} / \mathbf{s})$ & Excess Air Ratio & Furnace Temperature $\left({ }^{\circ} \mathbf{C}\right)$ & Mode \\
\hline OP1 & 90 & 1.2 & 1100 & F2 \\
OP2 & 90 & 1.2 & 900 & F2 \\
OP3 & 90 & 1.2 & 1000 & F2 \\
OP4 & 90 & 1.25 & 1100 & F2 \\
OP5 & 90 & 1.3 & 1100 & F2 \\
OP6 & 90 & 1.2 & 850 & F1 \\
\hline
\end{tabular}

For all cases, fuel and air without preheating temperature is $27^{\circ} \mathrm{C}$, and preheating air temperature is $850^{\circ} \mathrm{C}$. 


\section{Results and Discussion}

\subsection{Heat Flux Profile at Burner Horizontal Plane}

The contour profiles function in Origin software (OriginLab Corporation: Northhampton, MA, USA) was used to process the test data for all 14 measurement points, corresponding to observation holes at the furnace roof, in the burner horizontal plane. The average heat flux and maximum heat flux were determined based on the results.

\subsubsection{Total Heat Flux (THF) Profile}

The comparison depicted in Figure 5a-c suggests that the maximum THF were 344.4, 209.3, and $270.0 \mathrm{~kW} / \mathrm{m}^{2}$ for cases OP1-OP3, respectively. For OP1, the average THF was equal to $287.3 \mathrm{~kW} / \mathrm{m}^{2}$; it decreased to 174.0 and $237.6 \mathrm{~kW} / \mathrm{m}^{2}$ for OP2 and OP3, respectively. OP1 also had a larger high THF zone compared to OP3 or OP2. The temperature of the chamber wall was high enough to ensure that the temperature gradient was too small for the heat flux produced by combustion to be absorbed by the wall. In other words, increasing the furnace temperature makes the burner combustion more effective.

The comparison shown in Figure 5a,d,e suggests that maximum and average THF of OP4 were 302.2 and $242.2 \mathrm{~kW} / \mathrm{m}^{2}$, respectively. The maximum and average THF of OP5 were 280.4 and $218.7 \mathrm{~kW} / \mathrm{m}^{2}$. In regards to the heat flux distribution, THF decreased with increase in excess air ratio. Large excess air ratio enlarged the combustion zone, but reduced the flame size. A possible explanation for the relatively low average and maximum heat flux is the increased incomplete combustion loss and temperature of the exhaust gas caused by elevated excess air ratio.

The OP6 combustion mode was different from the other five cases, as mentioned above. The maximum and average THF of OP6 was 352.2 and $265.4 \mathrm{~kW} / \mathrm{m}^{2}$. The OP6 THF maximum was larger than that of OP1, but its THF average was lower. Conventional combustion creates an intense flame in a small space, but mild (or even no) combustion at a distance from the flame. Our results reveal that F1 combustion mode certainly affected the combustion efficiency, especially when there was a small combustion zone and small flame.

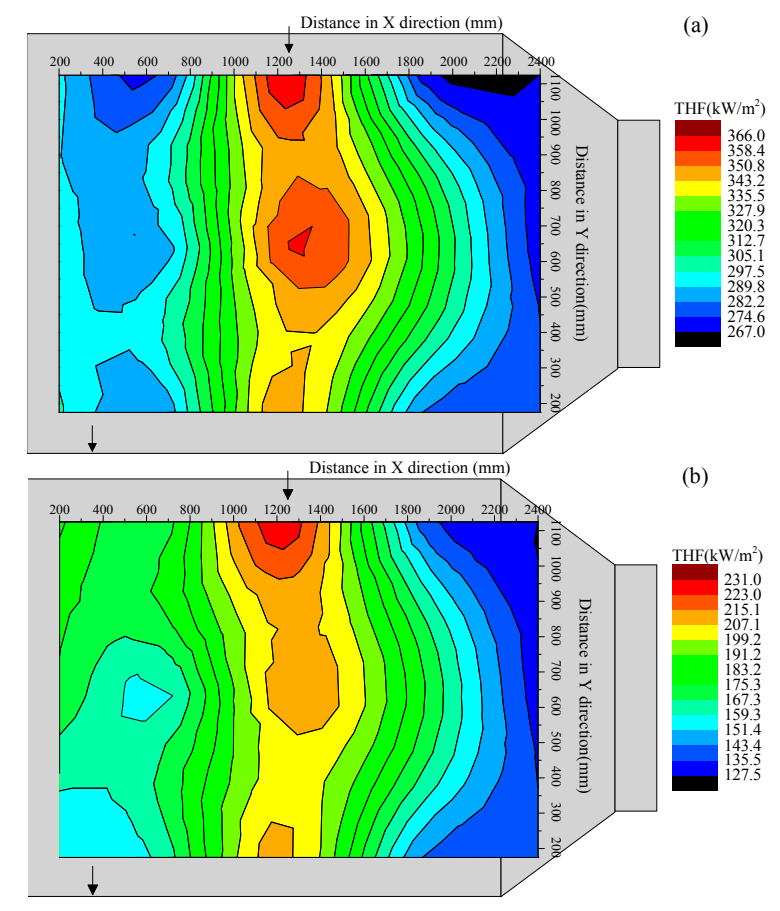

Figure 5. Cont. 


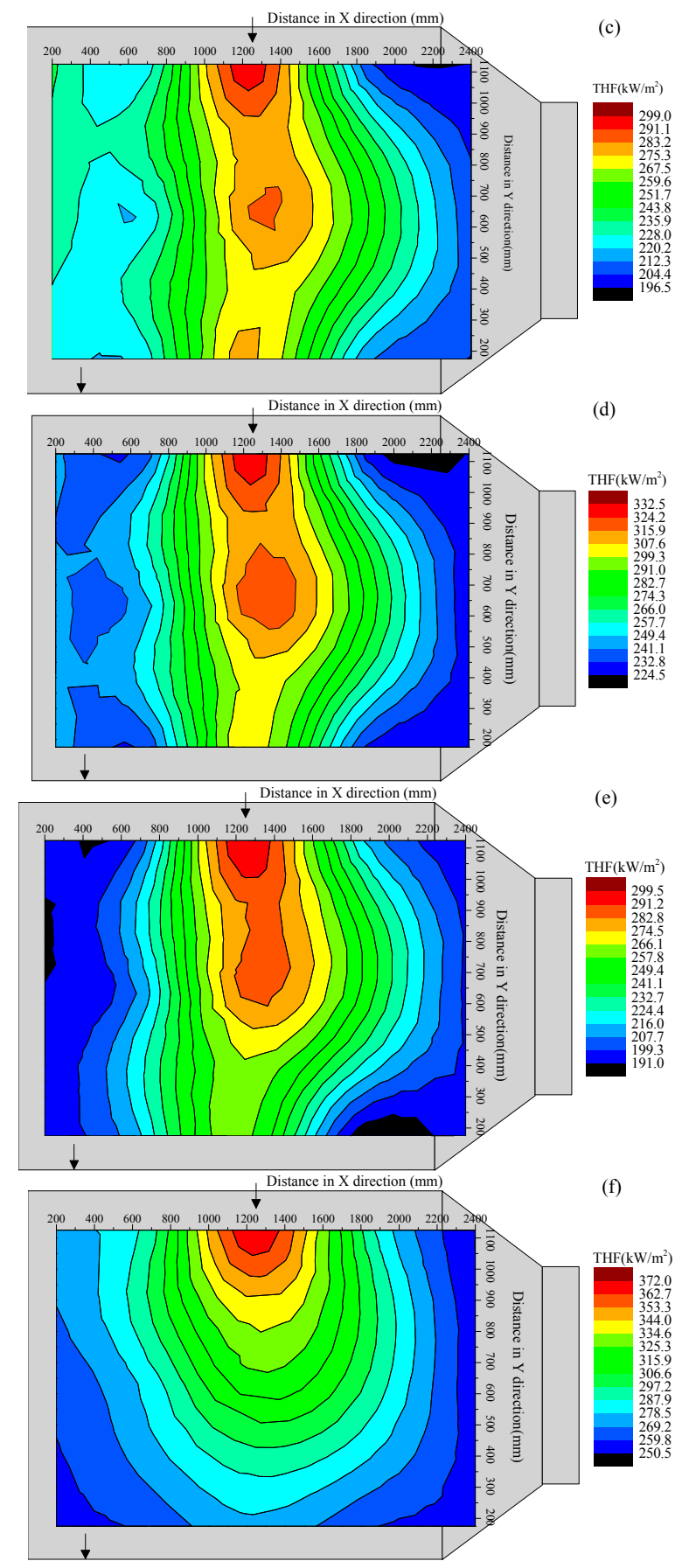

Figure 5. The total heat flux distribution at burner horizontal plane: (a) OP1; (b) OP2; (c) OP3; (d) OP4; (e) OP5; and (f) OP6.

Figure 6 shows the variations in THF with $Y$ distance in two lines placed at $X=350 \mathrm{~mm}$ and $X=1250 \mathrm{~mm}$. The THF value of the $X=1250 \mathrm{~mm}$ curve decreased with distance along the burner $\mathrm{B}$ axis. Changes in combustion mode and excess air ratio had a marked effect on slope of the THF curve while furnace temperature increased, however, some cases showed opposite variations trends (e.g., the $X=350 \mathrm{~mm}$ line) compared to the $X=1250 \mathrm{~mm}$ curve, such as OP2, OP3, and OP6. This may have been because the line was so near to the exit of the furnace. The other cases were only mildly affected by these changes in terms of total heat flux. 

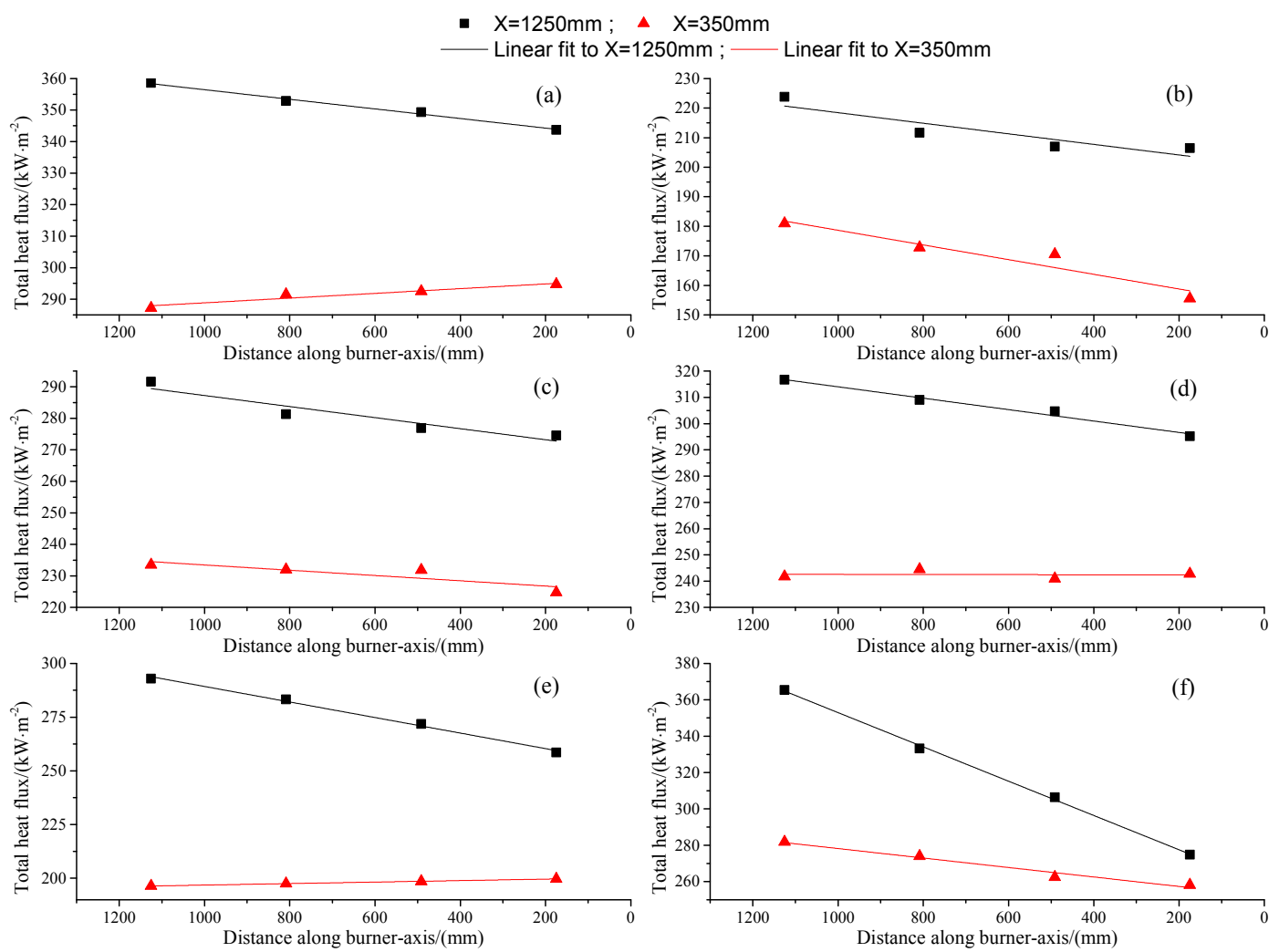

Figure 6. The total heat flux at $X=1250 \mathrm{~mm}$ and $X=350 \mathrm{~mm}$ as function of distance along burner-axis: (a) OP1; (b) OP2; (c) OP3; (d) OP4; (e) OP5; and (f) OP6.

\subsubsection{Radiation Heat Flux (RHF) Profile}

The comparison shown in Figure 7a-c indicates that the maximum RHF were 240.7, 144.5, and $191.6 \mathrm{~kW} / \mathrm{m}^{2}$ for OP1, OP2, and OP3, respectively. The average RHF were $237.1,133.4$, and $181.2 \mathrm{~kW} / \mathrm{m}^{2}$ for OP1, OP2, and OP3, respectively. High heat flux was located on the combustion zone and decreased evenly with distance; elevated furnace temperature enlarged the high heat flux area and thus improved the combustion. The variations in RHF may have been caused by several factors including differences in the radiation flux caused by furnace temperature.

Compared to OP1, if excess air ratio was increased to 1.25 , the maximum and average RHF were dropped to 216.6 and $208 \mathrm{~kW} / \mathrm{m}^{2}$, respectively. At even higher excess air ratios, the maximum and average RHF decreased to 194.4 and $186.7 \mathrm{~kW} / \mathrm{m}^{2}$. The lower heat flux parameters for OP4 and OP5 were likely caused by slower combustion rate due to increased excess air ratio. An increase of excess air ratio from 1.2 to 1.3 not only decreased heat flux, but also enlarged the heat flux gradient. The high heat flux zone was pushed to the center under these conditions, as well. In general, high excess air ratio caused non-uniform temperature and a fractured combustion route.

The maximum and average RHF were 209.4 and $168.0 \mathrm{~kW} / \mathrm{m}^{2}$ for OP6-lower than those of OP1-while the heat flux gradient of OP6 was higher than that of OP1. In effect, the radiation flux distribution of OP1 was more homogeneous than that of OP6. Flameless combustion mode exhibited better burning performance overall in regards to effectiveness and uniformity.

Figure 8 presents changes in the RHF curve along two lines $(X=1250 \mathrm{~mm}$ and $X=350 \mathrm{~mm}$ ). For the line $X=1250 \mathrm{~mm}$, the first three cases trended downward. The OP4 and OP5 curves formed ridge-like shapes. Curiously, the curve of OP6 was almost flat. Increasing the furnace temperature enlarged the slope of the curves: For $X=350 \mathrm{~mm}$, OP1 had a high $R H F$ value (close to $X=1250 \mathrm{~mm}$ ) at burner A; conversely, OP2 and OP3 had a low radiation heat flux at that point. OP4 and OP5 curves formed a small valley shape at the center. The RHF curve of OP6 started high and formed a large slope. 


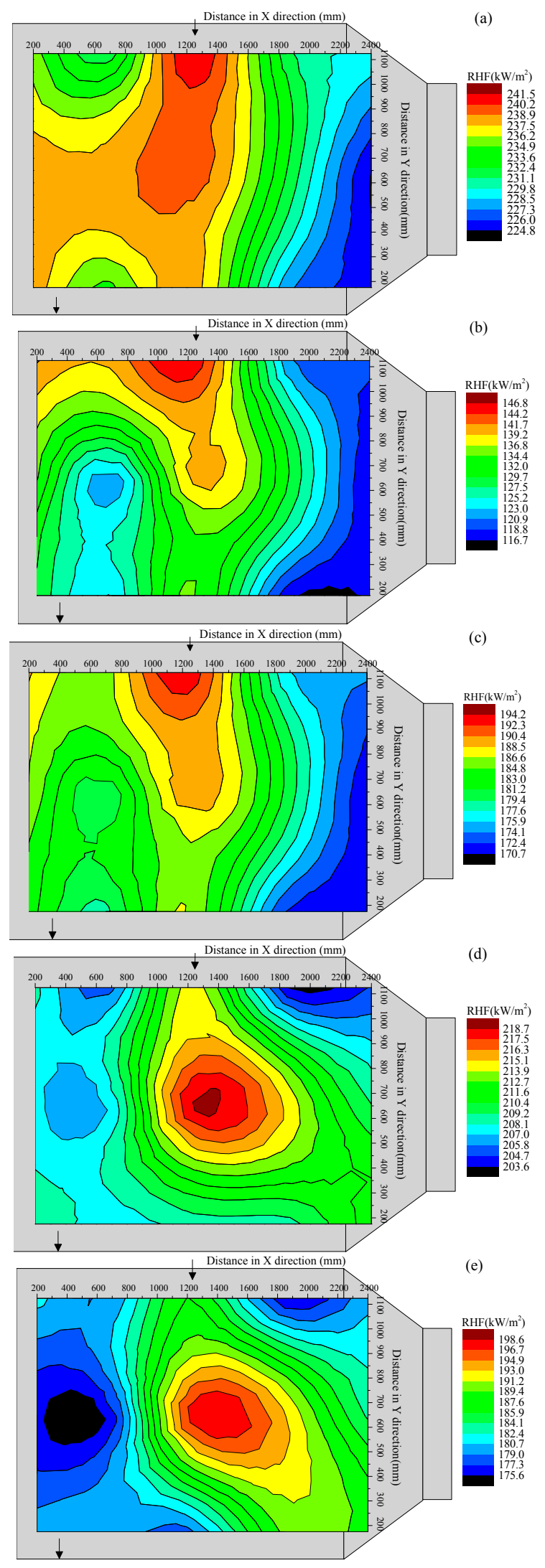

Figure 7. Cont. 


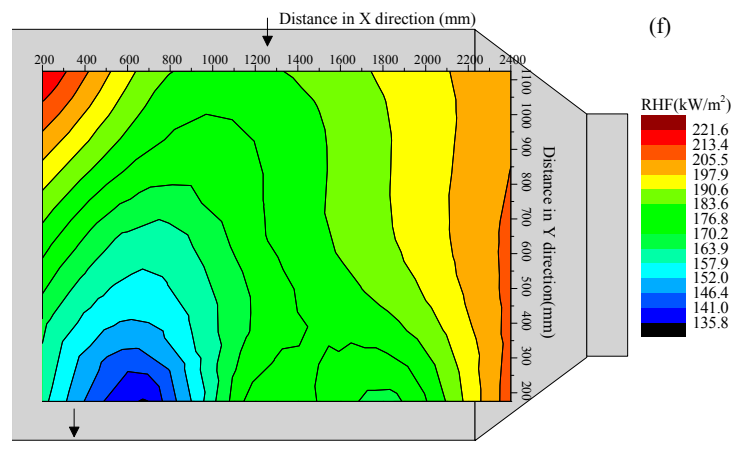

Figure 7. The radiation heat flux distribution at burner horizontal plane: (a) OP1; (b) OP2; (c) OP3; (d) OP4; (e) OP5; and (f) OP6.

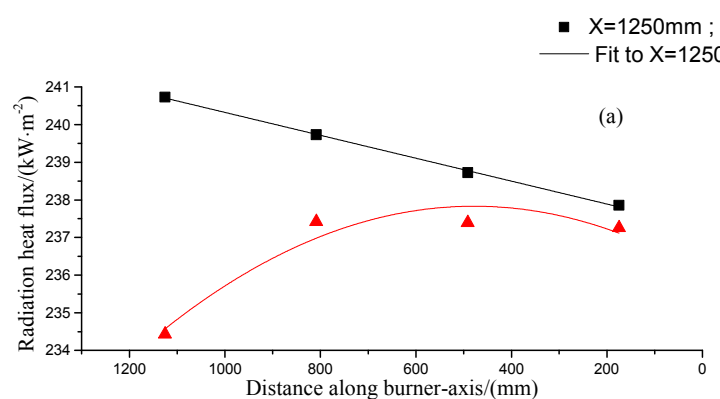

$\mathrm{X}=350 \mathrm{~mm}$
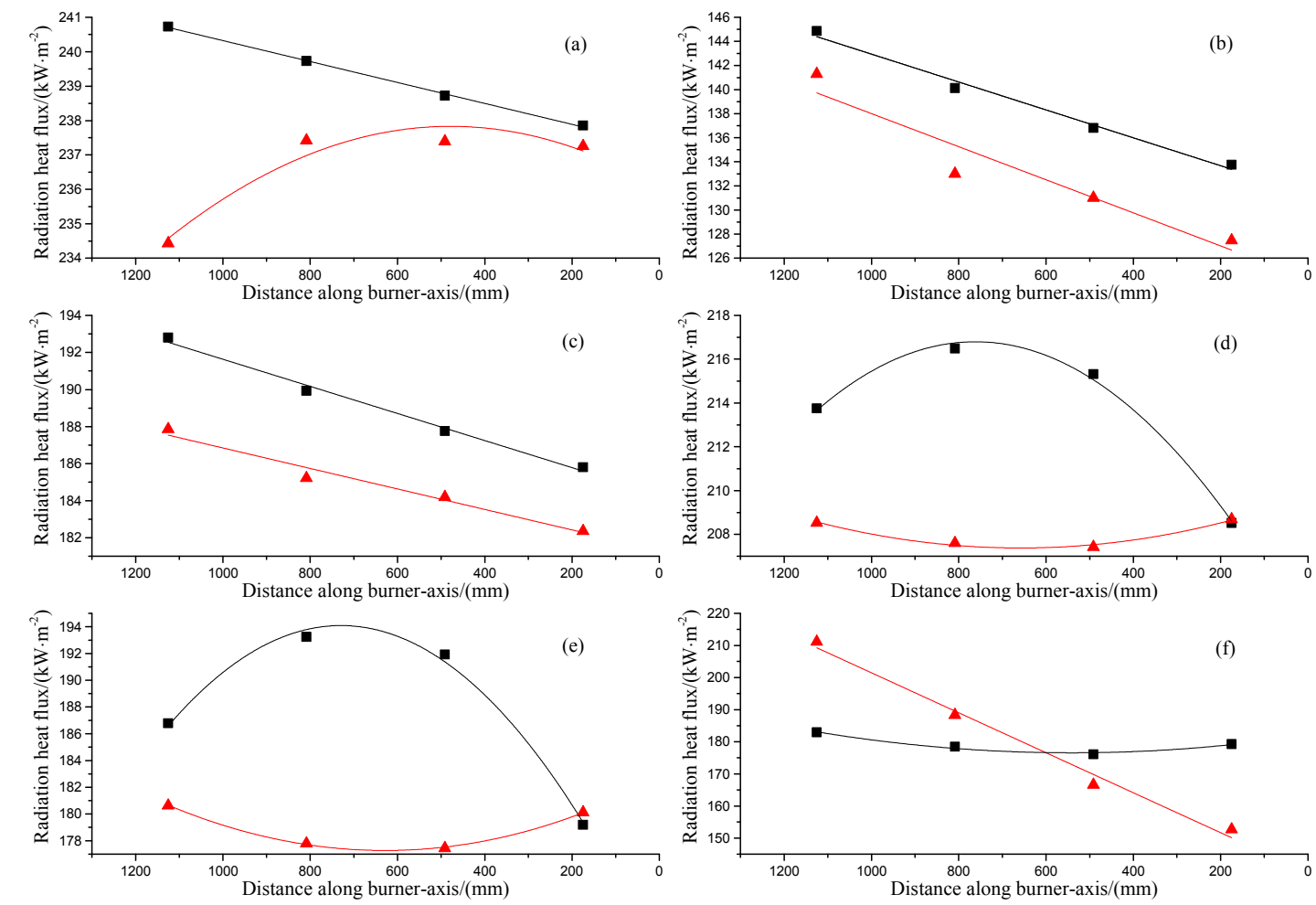

Figure 8. The radiation heat flux at $X=1250 \mathrm{~mm}$ and $X=350 \mathrm{~mm}$ as function of distance along burner-axis: (a) OP1; (b) OP2; (c) OP3; (d) OP4; (e) OP5; and (f) OP6.

\subsubsection{CHT Coefficient of Flame}

As convection heat flux changed with furnace temperature and excess air ratio, $\mathrm{CHT}$ coefficient of flame should be investigated. No. 6 and No. 8 holes were chosen as the experiment points to calculate CHT coefficient because they were situated at the axis of burner B. Figure $2 \mathrm{c}$ describes that No. 6 had a long distance from burner B (1275 mm), while No. 8 hole was closed to burner B, $325 \mathrm{~mm}$.

Figure 9 shows that the CHT coefficients of flameless combustion cases, measured in No. 6 hole, were almost equal to $30 \mathrm{~W} / \mathrm{m}^{2} \cdot \mathrm{k}$, but conventional combustion was $34.03 \mathrm{~W} / \mathrm{m}^{2} \cdot \mathrm{k}$. It is obvious that furnace temperature and excess air ratio had a mild effect on convection coefficient. Moreover, CHT coefficients of No. 8 hole are much higher than that of No. 6 hole. In No. 8 hole, OP6 had greatest $\mathrm{CHT}$ coefficient. The high values of $\mathrm{CHT}$ coefficients at proximal burner for OP6 can be a result of the 
relatively large convection heat flux in conventional combustion. It was also indirectly indicated that RHF occupy a central position in THF.

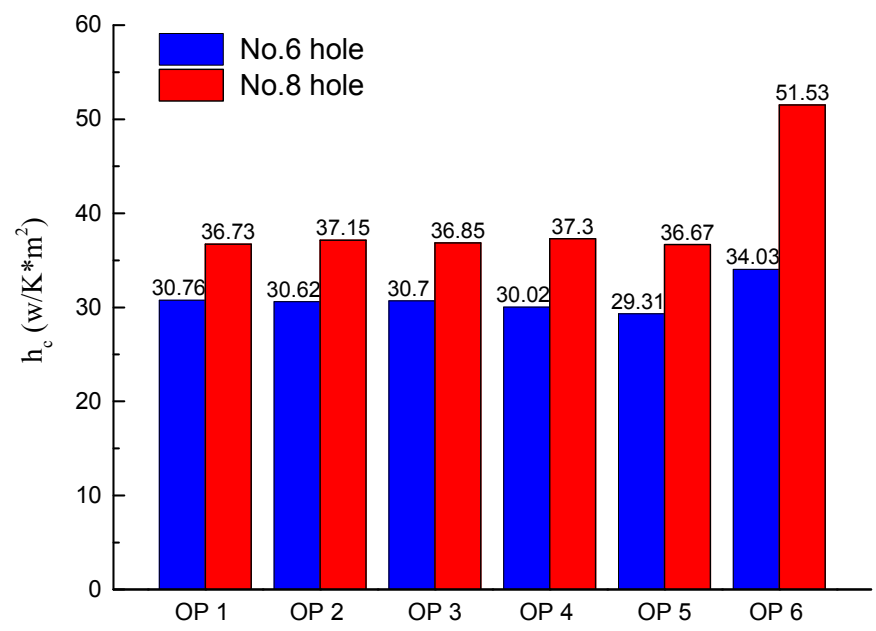

Figure 9. The convection heat transfer coefficient variation of six cases.

\subsection{Nonlinear Surface Fitting of THF Profile at Burner Horizontal Plane}

THF at the 14 measuring points were nonlinear surface-fitted to obtain an expression of the THF distribution at the burner horizontal plane. We used different equations for the fitting and then selected the best equation by comparison. Table 3 lists the THF equation of THF profiles at the burner plane in each operating condition. The $R$-sq (adj) values of the equations, i.e., their respective fitting degree, are given in Table 3. A polynomial equation was applied to describe flameless combustion and a Lorentz equation was used for the conventional combustion mode.

Table 3. Total heat flux equation of different operating conditions of six cases.

\begin{tabular}{cccc}
\hline Heat Flux & OP & Equation Form & R-sq (adj) \\
\hline \multirow{6}{*}{ THF } & OP1 & & 0.911 \\
& OP2 & $Q=Q_{0}+A_{1} x+A_{2} x^{2}+A_{3} x^{3}+A_{4} x^{4}+A_{5} x^{5}+B_{1} y+B_{2}$ & 0.897 \\
& OP3 & $y^{2}+B_{3} y^{3}+B_{4} y^{4}+B_{5} y^{5}$ & 0.881 \\
& OP4 & & 0.913 \\
& OP5 & & 0.876 \\
\cline { 2 - 4 } & OP6 & $Q=Q_{0}+A /\left(\left(1+\left(\left(x-x_{\mathrm{c}}\right) / w_{1}\right)^{2}\right) \times\left(1+\left(\left(y-y_{\mathrm{c}}\right) / w_{2}\right)^{2}\right)\right)$ & 0.958 \\
\hline
\end{tabular}

Note: Coefficients of each equation are shown in the Appendix A.

An observation hole on the wall located opposite of combustion burner B measured the heat flux at the burner axial plane. Six points were chosen from the axis and their Cartesian coordinates were defined: $(x=1250, y=200),(1250,400),(1250,600),(1250,800),(1250,1000)$, and $(1250,1200)$.

Figure 10 shows the THF of simulated and measured changes along the axis of burner B in different cases, as well as the fitting line about the measured points. The simulated and fitted line had almost the same slope as the equation; the fitting line was just slightly higher than the simulated line. The low values of intercept of the simulation results may be a result of scattered observation points at the whole burner plane (i.e., points that were not focused on the burner axis or combustion zone). It is therefore reasonable to attribute the intercept error to experimental errors. Said error could be eliminated if the observation points at the burner axis were increased, but, in general, the simulated results of each operating condition agreed with measured values. 

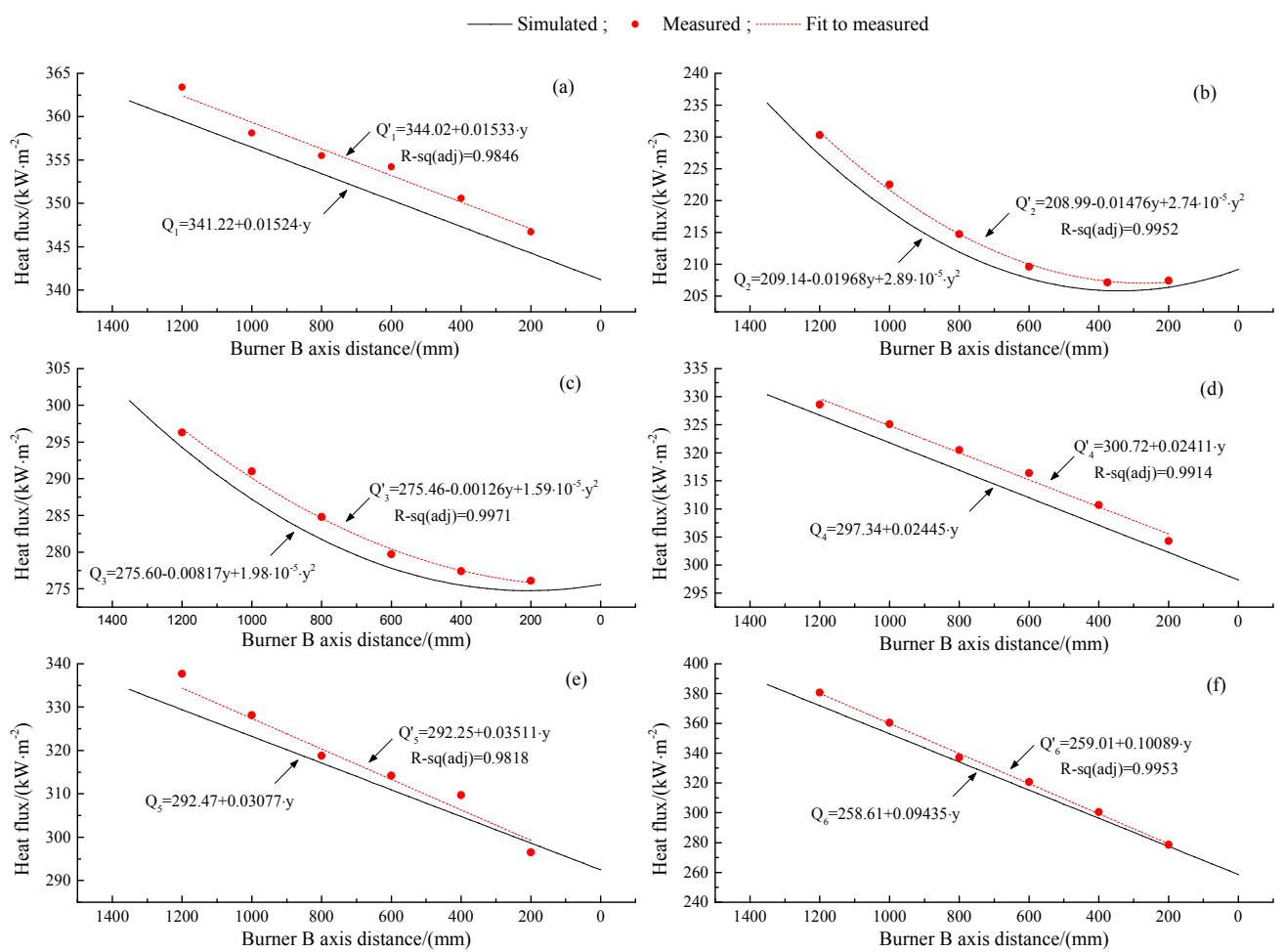

Figure 10. Heat flux as function of the distance along burner B axis: (a) OP1; (b) OP2; (c) OP3; (d) OP4; (e) OP5; and (f) OP6.

\subsection{Heat Flux Proportion at Three Horizontal Levels}

Heat flux distributions on the burner horizontal plane $(Z=0 \mathrm{~mm})$ are known to fluctuate with increase in height from $Z=0 \mathrm{~mm}$, so we researched these fluctuations under standard operating conditions (OP1). Two horizontal planes were set up away from the burner horizontal plane; horizontal plane height was 0,300 , and $550 \mathrm{~mm}$ for the burner plane, middle plane, and high plane, respectively. The No. 10 hole was selected as the observation point to measure heat flux, because it was situated in the middle between burner B and burner A.

Figure 11 shows where RHF accounted for about $80 \%$ of THF. By comparison among the three horizontal planes, the $550 \mathrm{~mm}$ plane had the maximum $T H F$ of $303.1 \mathrm{~kW} / \mathrm{m}^{2}$. The $R H F$ of the $550 \mathrm{~mm}$ plane was also the largest. In other words, heat flux is easier to concentrate at the furnace top when the combustion burner works properly.

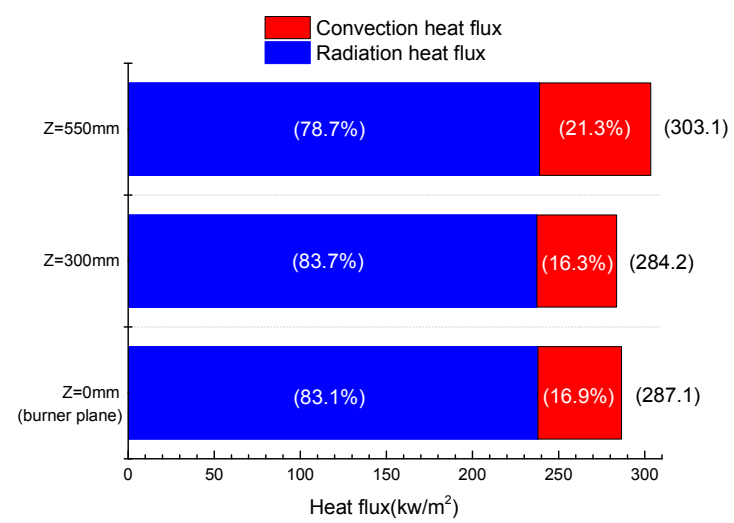

Figure 11. The heat flux measured from three height levels at No. 10 hole with standard operating condition. 


\section{Conclusions}

An experimental evolution of heat flux distribution in a reheating aluminum furnace with a pair of regenerative burners was conducted in this study. The main objective was to comprehensively investigate the heat flux characteristics in a typical furnace based on experimental data. Ultimately, we sought to develop a combustion model that can be utilized to accurately simulate heat transfer in the furnace. Our most important observations can be summarized as follows.

- The maximum and average THF increased (64.5\% and $65.1 \%)$ as furnace temperature increased from 900 to $1100{ }^{\circ} \mathrm{C}$. Increasing the excess air ratio from 1.2 to 1.3 at $1100 \mathrm{~K}$ furnace temperature enlarged the maximum and average THF (22.8\% and $23.4 \%)$, the high THF area and reduced the flame volume. Conventional combustion resulted in lower average THF (8.3\%) and smaller combustion space than flameless combustion.

- The maximum and average RHF were enhanced (25.6\% and $30.8 \%$ ) by elevated furnace temperatures (900 to $1100{ }^{\circ} \mathrm{C}$ ), and $23.8 \%$ and $27.0 \%$ by magnified excess air ratio (1.2 to 1.3 ). Although an increase in excess air ratio contributed to the maximum $R H F$, it also caused the heat flux gradient to enlarge. The RHF distribution of flameless combustion was more homogeneous than that of conventional combustion.

- A variation of furnace temperature and excess air ratio had mildly effect (above 20\%) on convection coefficient, but combustion mode was in contrast (51.4\%).

- The estimated model of the heat flux distribution from the measured heat flux at the whole burner plane agreed with the fitted line of the axis of burner B.

- The RHF of three horizontal levels occupied about $80 \%$ of the total heat flux. Heat flux tended to concentrate on the top of the furnace.

Acknowledgments: The authors thank National Natural Science Foundation of China (NSFC) (No. 51276023) and NSFC International Cooperation and Exchange (No. 513101410) for supporting this work. The authors also wish to thank YeChiu Metal Resource Recycling (China) Ltd (Suzhou, China).

Author Contributions: Hang Zhang and Shengxiang Deng conceived and designed the experiments; Hang Zhang performed the experiments; Shengxiang Deng contributed reagents/materials/analysis tools; Hang Zhang wrote the paper.

Conflicts of Interest: The authors declare no conflict of interest.

\section{Appendix A}

Table A1. The coefficient of THF heat flux equation with different operation conditions.

\begin{tabular}{cccccccc}
\hline Coefficient & OP1 & OP2 & OP3 & OP4 & OP5 & Coefficient & OP6 \\
\hline$q_{0}$ & 244.6823 & 134.0883 & 190.4299 & 201.068 & 176.2513 & $q_{0}$ & 250.34332 \\
$A_{1}$ & -2.22729 & -1.35071 & -1.79064 & -1.80963 & -1.43322 & $A$ & 126.79834 \\
$A_{2}$ & 0.00594 & 0.00366 & 0.0048 & 0.0049 & 0.0038 & $x_{\mathrm{c}}$ & 1214.22684 \\
$A_{3}$ & $-6.6 \times 10^{-6}$ & $-4.2 \times 10^{-6}$ & $-5.4 \times 10^{-6}$ & $-5.6 \times 10^{-6}$ & $-4.3 \times 10^{-6}$ & $w_{1}$ & 417.5452 \\
$A_{4}$ & $3.11 \times 10^{-9}$ & $2 \times 10^{-9}$ & $2.55 \times 10^{-9}$ & $2.68 \times 10^{-9}$ & $2.12 \times 10^{-9}$ & $y_{\mathrm{c}}$ & 1022.544 \\
$A_{5}$ & $-5.2 \times 10^{-13}$ & $-3.4 \times 10^{-13}$ & $-4.3 \times 10^{-13}$ & $-4.6 \times 10^{-13}$ & $-3.6 \times 10^{-13}$ & $w_{2}$ & 443.1504 \\
$B_{1}$ & 0.05254 & 0.04959 & 0.04932 & 0.05302 & 0.05323 & \\
$B_{2}$ & $-6.8 \times 10^{-6}$ & $6.3 \times 10^{-6}$ & $-1.3 \times 10^{-6}$ & $-1.3 \times 10^{-6}$ & $1.8 \times 10^{-6}$ & \\
$B_{3}$ & $-8.8 \times 10^{-5}$ & $-4.7 \times 10^{-5}$ & $-6.7 \times 10^{-5}$ & $-7.3 \times 10^{-5}$ & $-6.2 \times 10^{-5}$ & \\
$B_{4}$ & $2.1 \times 10^{-7}$ & $1.1 \times 10^{-7}$ & $1.6 \times 10^{-7}$ & $1.7 \times 10^{-7}$ & $1.5 \times 10^{-7}$ & \\
$B_{5}$ & $-1.2 \times 10^{-10}$ & $-6.2 \times 10^{-11}$ & $-8.9 \times 10^{-11}$ & $-9.7 \times 10^{-11}$ & $-8.2 \times 10^{-11}$ & \\
\hline
\end{tabular}

\section{References}

1. Steinboeck, A.; Wild, D.; Kugi, A. Energy-efficient control of continuous reheating furnaces. IFAC Proc. Vol. 2013, 46, 359-364. [CrossRef]

2. Marion, M.; Hirz, R.P.; Grote, F.; Weber, S.; Winning, G.; Adler, W.; Bender, W. Increase of energy efficiency of reheating furnaces in forging mills. Stahl Und Eisen 2008, 128, 29-33. 
3. Xing, F.; Kumar, A.; Huang, Y.; Chan, S.N.; Ruan, C.; Gu, S.; Fai, X.L. Flameless combustion with liquid fuel: A review focusing on fundamentals and gas turbine application. Appl. Energy 2017, 197, 28-51. [CrossRef]

4. Mahdi, Y.; Ann, F.; Thierry, G. Impact of size and temperature on the hydrodynamics of chemical combustion. Appl. Energy 2015, 157, 416-421.

5. Bhuiyan, A.A.; Blicblau, A.S.; Sadrul Islam, A.K.M.; Naser, J. A review on thermo-chemical characteristics of coal/biomass co-firing in industrial furnace. J. Energy Inst. 2016, in press. [CrossRef]

6. Chiara, G.; Giovanni, C.; Leonardo, T. Numerical investigation of oxy-natural-gas combustion in a semi-industrial furnace: Validation of CFD sub-models. Fuel 2013, 109, 445-460.

7. Zhang, R.Q.; Yang, H.R.; Hu, N.; Lu, J.F.; Wu, Y.X. Experimental investigation and model validation of the heat flux profile in a $300 \mathrm{MW}$ CFB boiler. Powder Technol. 2013, 246, 31-40. [CrossRef]

8. Xu, L.J.; Cheng, L.M.; Cai, Y.; Liu, Y.Q.; Wang, Q.H.; Luo, Z.Y.; Ni, M.J. Heat flux determination based on the waterwall and gas-solid flow in a supercritical CFB boiler. Appl. Therm. Eng. 2016, 99, 703-712. [CrossRef]

9. Roldán, M.I.; Monterreal, R. Heat flux and temperature prediction on a volumetric receiver installer in a solar furnace. Appl. Energy 2014, 120, 65-74. [CrossRef]

10. Robin, P.M.; Shaun, M.F.; Zuzana, G.; Juraj, L. An experimental-numerical method for estimating heat transfer in a Bridgman furnace. Appl. Therm. Eng. 2014, 67, 61-71.

11. Gimelli, A.; Muccillo, M.; Sannino, R. Optimal design of modular cogeneration plants for hospital facilities and robustness evaluation of the results. Energy Convers. Manag. 2017, 134, 20-31. [CrossRef]

12. Kang, Y.H.; Wang, Q.H.; Lu, X.F.; Ji, X.Y.; Wang, H.; Guo, Q.; Chen, Y.; Yan, J.; Zhou, H.L. Experimental and theoretical study on radiative heat transfer characteristics of dimethyl ether jet diffusion flame. Fuel 2015, 158, 684-696. [CrossRef]

13. Hashimoto, N.; Watanabe, H. Numerical analysis on effect of furnace scale on heat transfer mechanism of coal particles in pulverized coal combustion field. Fuel Process. Technol. 2016, 145, 20-30. [CrossRef]

14. Zhang, D.L.; Meng, C.W.; Zhang, H.; Liu, P.Y.; Li, Z.H.; Wu, Y.X.; Lu, J.F.; Zhou, W.; Ran, S.M.; Zhang, D.H. Studies on heat flux distribution on the membrane walls in a $600 \mathrm{MW}$ supercritical arch-fired boiler. Appl. Therm. Eng. 2016, 103, 264-273. [CrossRef]

15. Fan, Q.W.; Hui, S.E.; Zhou, Q.L.; Chen, X.; Zhao, Q.X.; Xu, T.M. Experimental study on the heat flux distribution of a laboratory-scale wall-fired furnace. Energy Fuels 2010, 24, 5369-5377. [CrossRef]

16. Silva, R.C.; Krautz, H.J. Experimental studies on heat transfer of oxy-coal combustion in a large-scale laboratory furnace. Appl. Therm. Eng. 2015, 82, 82-97. [CrossRef]

17. Wang, J.M.; Xu, P.; Yan, H.J.; Zhou, J.M.; Li, S.X.; Gui, G.C.; Li, W.K. Burner effects on melting process of regenerative aluminum melting furnace. Trans. Nonferrous Met. Soc. China 2013, 23, 3125-3136. [CrossRef]

18. Sadegh, S.K.; David, P.; Fredirk, N.; Filip, J. Heat transfer in a 4-MWth circulating fuildized bed furnace operated under oxy-fired and air-fired conditions: Modeling and measurements. Int. J. Greenh. Gas Control 2015, 37, 264-273.

19. Erfan, K.; Mahdi, P.; Mohammad, H.P. Effects of excess air and preheating on the flow pattern and efficiency of the radiative section of a fired heater. Appl. Therm. Eng. 2016, 105, 537-548.

20. Karimi, H.J.; Saidi, M.H. Heat transfer and energy analysis of a pusher type reheating furnace using oxygen enhanced air for combustion. J. Iron Steel Res. 2010, 17, 12-17. [CrossRef]

21. Jang, J.H.; Lee, D.E.; Kim, C.M.; Kim, M.Y. Prediction of furnace heat transfer and its influence on the steel slab heating and skid mark formation in a reheating furnace. Iron Steel Inst. J. Int. 2008, 48, 1325-1330. [CrossRef]

22. Wikstrom, P.; Blasiak, W.; Berntsson, F. Estimation of the transient surface temperature, heat flux and effective heat transfer coefficient of a slab in an industrial reheating furnace by using an inverse method. Steel Res. Int. 2007, 78, 63-70. [CrossRef]

23. Rafidi, N.; Blasiak, W. Heat transfer characteristics of HiTAC heating furnace using regenerative burners. Appl. Therm. Eng. 2006, 26, 2027-2034. [CrossRef]

24. Bideau, P.L.; Ploteau, J.P.; Glouannec, P. Heat flux estimation in an infrared experimental furnace using an inverse method. Appl. Therm. Eng. 2009, 29, 2977-2982. [CrossRef]

25. Sankar, G.; Rao, A.C.; Seshadri, P.S.; Balasubramanian, K.R. Techniques for measurement of heat flux in furnace waterwalls of boilers and prediction of heat flux-A review. Appl. Therm. Eng. 2016, 103, 1470-1479. [CrossRef] 
26. Murthy, A.V. Characterization of an ellipsoidal radiometer. J. Res. Natl. Inst. Stand. Technol. 2003, 108, 115-124. [CrossRef] [PubMed]

27. Li, A.; Gao, X.P. A method to calculate wall heat fluxes of electrical equipments based on overdetermined linear equation. Appl. Therm. Eng. 2011, 114, 428-443. [CrossRef]

28. Holman, S.W. Discussion of the Precision of Measurements: With Examples Taken Mainly from Physics and Electrical Engineering; Brunton Press: Louisville, CO, USA, 2007. 